\title{
A (IN) SUSTENTABILIDADE DOS CONCEITOS DE INIMPUTABILIDADE E DE PERICULOSIDADE DIANTE DA REFORMA PSIQUIÁTRICA
}

Gustavo Dalul Faria ${ }^{170}$

Recebido em: $17 / 10 / 2017$

Aprovado em: 26/12/2017

\begin{abstract}
RESUMO
O presente artigo tem como objetivo discutir o instituto da medida de segurança como modalidade de resposta jurídica, bem como conceitos de periculosidade e de inimputabilidade que se relacionam com o instituto, à luz da Reforma Psiquiátrica (Lei 10.216/01), que inaugurou um novo paradigma, tendo como foco não mais a doença, mas a pessoa; não mais a cessação de periculosidade, mas a reinserção social da pessoa com transtorno mental em conflito com a lei.
\end{abstract}

Palavras-chave: Medida de segurança. Reforma psiquiátrica: periculosidade. Inimputabilidade.

\section{INTRODUÇÃO}

O objetivo do presente artigo é discutir o instituto da medida de segurança como modalidade de resposta jurídica, bem como conceitos de periculosidade e imputabilidade que se relacionam com o instituto, à luz da Lei de Reforma Psiquiátrica (Lei 10.612/01).

Usaremos como ponto de partida para o nosso debate, o Caso Cadu, que causou grande repercussão nacional, envolvendo indivíduo sujeito à medida de segurança, por prática anterior de duplo homicídio, e que, durante o curso da medida, em tratamento ambulatorial, comete 2 (dois) latrocínios.

Carlos Eduardo Sundfeld Nunes (Cadu) foi julgado pela acusação de duplo homicídio contra o cartunista Glauco e seu filho Raoni, fato ocorrido no ano de 2010, na cidade de Osasco - SP. Durante a instrução daquele processo, foi instaurado incidente de insanidade

\footnotetext{
${ }^{170}$ Mestrando em Direito Constitucional pelo Instituto Brasiliense de Direito Público - IDP. Especialista em Direito Processual Penal pela UFG-GO. Especialista em Direito Constitucional pelo IDP/UNISUL e Juiz de Direito da $5^{\text {a }}$ Vara Criminal da Comarca de Goiânia - GO.
} 
mental do acusado, que concluiu por sua inimputabilidade. De consequência, foi proferida sentença de absolvição imprópria, aplicando-lhe medida de segurança.

O cumprimento da medida de segurança foi transferido para a Comarca de Goiânia GO, onde residia sua família, o que lhe permitiria uma melhor assistência e uma maior possibilidade de reinserção social.

No decorrer do cumprimento da medida de segurança, Cadu foi beneficiado com a mudança de regime, da internação para o tratamento ambulatorial, visando sua gradual reinserção ao meio social, com o apoio de equipe multidisciplinar do programa PAILI ${ }^{171}$, bem como com o apoio de sua família.

No curso do tratamento ambulatorial, Cadu foi acusado da prática de 2 (dois) latrocínios, em um intervalo de 3 (três) dias, quando então foi preso. Durante a instrução processual, foi instaurado novo incidente de insanidade mental, que constatou que Cadu era imputável por ocasião da prática dos fatos que lhe eram atribuídos. Foi condenado, no ano de 2015, a pena de 61 (sessenta e um) anos de prisão em regime fechado, por 2 (dois) latrocínios, receptação e porte de arma. Não recorreu. Atualmente cumpre pena em regime fechado, na Penitenciária Odenir Guimarães, em Goiás, e não mais a medida de segurança anteriormente estabelecida.

O Caso Cadu reacende o debate em torno do instituto da medida de segurança, permitindo a discussão crítica em torno da adequação desta modalidade de resposta jurídica, bem como de conceitos como a periculosidade e a imputabilidade, à luz da Lei Antimanicomial.

Com a pretensão de abordar a questão da resposta jurídica adequada à pessoa com transtorno mental em conflito com a lei, à luz da reforma psiquiátrica de 2011, que introduziu um novo paradigma na relação deste indivíduo com a lei penal, tecendo críticas à medida de segurança, à periculosidade como fundamento da coação estatal, bem como ao conceito de inimputabilidade, dividimos o presente artigo da seguinte maneira:

Inicialmente, trataremos no ponto 2 da evolução da legislação brasileira em relação à resposta jurídica dada à pessoa com transtorno mental em conflito com a lei, a partir do Código Criminal do Império de 1830, passando pelo Código Penal de 1890, pelo Código Penal de 1940 até sua reforma da parte geral em 1984. Neste período, diversos sistemas foram adotados (como aplicação de resposta penal), passando pela internação compulsória do

${ }^{171}$ O Paili - Programa de atenção integral ao louco infrator, implantado em Goiás, disponibiliza ao indivíduo sujeito à medida de segurança atenção por equipe multidisciplinar, tanto na internação como no tratamento ambulatorial, em conformidade com as diretrizes fixadas na Lei da Reforma Psiquiátrica, visando um tratamento capaz de resgatar a cidadania do indivíduo e de permitir sua reinserção social. 
indivíduo perigoso, aplicação do sistema do duplo binário, onde pena e medida de segurança poderiam ser aplicadas simultânea ou sucessivamente, até chegarmos no sistema vicariante, onde as penas são aplicadas aos imputáveis e as medidas de segurança aos inimputáveis.

Trataremos no ponto 3, da disciplina da legal vigente que estabelece as espécies de medida de segurança (internação e tratamento ambulatorial), os locais de cumprimento das medidas, o critério para a definição da espécie a ser aplicada, o tempo mínimo de imposição da medida, bem como sua duração por tempo indeterminado (até que, por perícia médica, seja constatada a cessação de periculosidade do inimputado).

No ponto 4, apresentaremos o sistema de responsabilidade penal brasileiro composto pelo "sistema da culpabilidade e pelo sistema da periculosidade" ${ }^{172}$. O primeiro sistema estabelece a aplicação de pena ao indivíduo imputável, a quem a lei atribui responsabilidade penal. O segundo sistema estabelece a aplicação de medida de segurança ao indivíduo inimputável, que, por doença mental ou desenvolvimento mental incompleto ou retardado, era, ao tempo da ação ou da omissão, inteiramente incapaz de entender o caráter ilícito do fato ou de determinar-se de acordo com esse entendimento.

No ponto 5 iremos abordar a mudança de paradigma proporcionado pela Lei da Reforma Psiquiátrica - Lei 10.216/2001, que busca, por meio do tratamento de saúde multidisciplinar, resgatar a cidadania da pessoa com transtorno mental, com a finalidade permanente de reinserção social em seu meio, priorizando os recursos extra-hospitalares à internação, abandonando as práticas asilares em manicômios e instituições totais.

No ponto 6 analisaremos o instituto da medida de segurança, à luz da reforma psiquiátrica, que nos permite tecer críticas quanto à possibilidade de sua perpetuidade (o que a tornaria mais severa que a pena), ao tratamento legal discriminatório da pessoa com transtorno mental em comparação com o apenado, à ausência de um regime jurídico de direitos e garantias fundamentais e ao seu caráter retributivo-punitivo-segregatório.

A atribuição de uma maior responsabilidade à pessoa com transtorno mental a partir da reforma psiquiátrica, o abandono do termo "doença mental" e a finalidade permanente de reinserção social, preconizadas pela Reforma Psiquiátrica serão tratadas no ponto 7. Elas permitem uma rediscussão a respeito do conceito de inimputabilidade, que pressupõe a ausência de responsabilidade penal e do conceito de periculosidade, fundamento da medida de segurança.

172 As expressões sistema de periculosidade e sistema da culpabilidade, com subdivisão do sistema de responsabilidade criminal, foram tomadas de empréstimo da obra de Salo de Carvalho. (CARVALHO, Salo de. Penas e medidas de segurança no direito penal brasileiro: fundamentos e aplicação judicial. São Paulo: Saraiva. 2013). 
A lei de reforma psiquiátrica impõe a reflexão a respeito do instituto da medida de segurança como resposta (in) adequada à pessoa com transtorno mental em conflito com a lei, a discussão a respeito da readequação do conceito de inimputabilidade e do afastamento da periculosidade como fundamento da medida de segurança. Essa é a discussão que pretendemos desenvolver neste artigo.

\section{EVOLUÇÃO DA LEGISLAÇÃO BRASILEIRA}

A legislação criminal brasileira conferiu diferente tratamento à pessoa com transtorno mental ao longo de sua história. Inicialmente, este indivíduo, ao praticar um fato tipificado como crime, não recebia nenhuma resposta jurídica. O Código Criminal do Império, de 1830, fundamentava a responsabilidade penal no livre arbítrio ${ }^{173} \mathrm{e}$, desta forma, os doentes mentais que não possuíam capacidade de discernimento não eram afetados com a imposição de pena ao praticarem fato tipificado como crime. Eles eram recolhidos junto às suas famílias ou em casas com destinação específica para eles, conforme decisão judicial ${ }^{174}$.

Com Código Penal de 1890, foi instituída a possibilidade de se determinar a internação compulsória, em estabelecimentos especializados, da pessoa com transtorno mental em conflito com a lei, quando o caso exigisse a "segurança do público ${ }^{175 " . ~ E s t a ~ p r a ́ t i c a ~ a s i l a r ~}$ normatizada se constituía em uma forma de "segregação daqueles que, a despeito de não terem responsabilidade sobre o fato cometido, eram indesejados e necessitavam ser apartados do convívio com o grupo em nome da defesa social ${ }^{176 "}$.

\footnotetext{
${ }^{173}$ A teoria do livre-arbítrio, fruto da Escola Clássica, argumenta que o homem é moralmente livre para fazer suas escolhas. "O fundamento da responsabilidade penal está na responsabilidade moral do indivíduo, sendo que esta, ou seja, a responsabilidade moral tem por base o livre-arbítrio". (GRECO, Rogério. Curso de Direito Penal - Parte Geral. Volume I. Editora Impetus. 15 Edição. 2013. p. 373.

${ }^{174}$ Assim dispunha o Código Criminal do Império: Art. 10. Também não se julgarão criminosos: (...); $2^{\circ} \mathrm{Os}$ loucos de todo o gênero, salvo se tiverem lúcidos intervalos, e neles cometerem o crime. Art. 12. Os loucos que tiverem cometido crimes serão recolhidos às casas para eles destinadas, ou entregues ás suas famílias, como ao Juiz parecer mais conveniente. http://www.planalto.gov.br/ccivil_03/leis/LIM/LIM-16-12-1830.htm

${ }^{175}$ Assim dispunha o Código Penal de 1890: Art. 27. Não são criminosos: (...); § $3^{\circ}$ Os que por imbecilidade nativa, ou enfraquecimento senil, forem absolutamente incapazes de imputação. Art. 29. Os individuos isentos de culpabilidade em resultado de affecção mental serão entregues a suas familias, ou recolhidos a hospitaes de alineados, si o seu estado mental assim exigir para segurança do publico. http://legis.senado.gov.br/legislacao/ListaPublicacoes.action?id=66049

176 PRADO, Alessandra Rapassi Mascarenhas. Tratamento Extra-Hospitalar: Possibilidade de Adoção em Crimes Punidos com Reclusão. In: SCARPA, Antonio Oswaldo; EL HIRECHE, Gamil Foppel (Coord.). Temas de Direito Penal e Processual Penal - Estudos em homenagem ao Juiz Tourinho Neto. Salvador: Editora JusPodium, 2013. p. 55.
} 
Já no final do século XIX, passou-se a justificar a intervenção penal não mais em razão do livre-arbítrio, "mas da periculosidade demonstrada por aquele que pratica um crime e da necessidade de prevenir que delitos voltassem a ser cometidos, para defesa do grupo social $^{177}$,

Com o desenvolvimento da ideia de periculosidade, passou-se à aplicação de medida de segurança à pessoa com transtorno mental em conflito com a lei, com a finalidade de contensão de sua periculosidade e da necessidade de prevenção de prática de futuros delitos.

A partir do Código Penal de $1940^{178}$, foi adotado o sistema duplo binário, onde aquele que praticava um fato tipificado como crime, em estado de perigoso e com capacidade de voltar a delinquir, passou a receber uma resposta jurídica própria. Agora não só a pessoa com transtorno mental, mas também o indivíduo que, mesmo imputável ou semi-imputável, mas que reconhecido em estado de perigoso, estariam sujeitos a receber uma combinação de pena e medida de segurança, que poderiam ser simultâneas ou sucessivas ${ }^{179}$.

De acordo com o Código Penal de 1940, duas eram as "hipóteses de configuração do

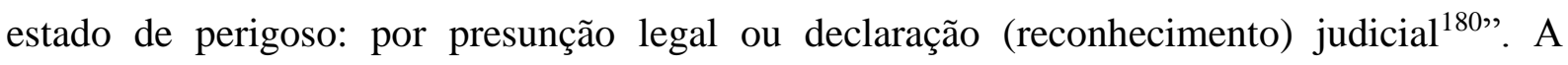
gravidade do delito e "não as necessidades do doente mental, determinava o tipo de medida de segurança, seguindo a mesma proporcionalidade que deveria reger a previsão e aplicação da pena $^{181 \%}$.

O sistema do duplo binário vigeu até a Reforma da Parte Geral de 1984, quando se instituiu o sistema vicariante, estabelecendo a aplicação de pena para o imputável e de medida

\footnotetext{
177 PRADO, Alessandra Rapassi Mascarenhas. Op. cit, p. 56. Destaca ainda que "no final do século XIX, desenvolvem-se teorias que estudam o crime e o delinquente do ponto de vista antropológico, social e físico, pautadas no biodeterminismo, em características biopsíquicas do delinquente, bem como na idéia de aplicação da sanção como forma de defesa social e de prevenção especial". A medida de segurança passa a existir ao lado da pena para completá-la ou substituí-la.

178 O Código Penal de 1940, que recebeu forte influência do Código Penal Italiano de 1930 (conhecido como Código Rocco), adotou o sistema do duplo binário, permitindo a aplicação cumulativa de pena e medida de segurança ao indivíduo socialmente perigoso.

${ }^{179}$ Assim dispunha o Código Penal de 1940: Verificação da periculosidade Art. 77. Quando a periculosidade não é presumida por lei, deve ser reconhecido perigoso o agente: I - se seus antecedentes e personalidade, os motivos determinantes e as circunstâncias do fato, os meios empregados e os modos de execução, a intensidade do dolo ou o grau da culpa, autorizam a suposição de que venha ou torne a delinqüir; II - se, na prática do fato, revela torpeza, perversão, malvadez, cupidez ou insensibilidade moral. (com redação dada pela Lei Lei n. 6416/1977 - http://legis.senado.gov.br/legislacao/ListaTextoIntegral.action?id=100306\&norma=124015 ). Presunção de periculosidade Art. 78. Presumem-se perigosos: I - aqueles que, nos termos do art. 22, são isentos de pena; (inimputáveis); II - os referidos no parágrafo único do artigo 22; (semi-imputáveis); III - os condenados por crime cometido em estado de embriaguez pelo álcool ou substância de efeitos análogos, se habitual a embriaguez; IV - os reincidentes em crime doloso; V - os condenados por crime que hajam cometido como filiados a associação, bando ou quadrilha de malfeitores. http://legis.senado.gov.br/legislacao/ListaPublicacoes.action?id=102343 .

${ }^{180}$ CARVALHO, Saulo de. Penas e medidas de segurança no direito penal brasileiro: fundamentos e aplicação judicial. São Paulo: Saraiva. 2013. p.504.

${ }^{181}$ PRADO, Alessandra Rapassi Mascarenhas. Op. cit, p. 58.
} 
de segurança ao inimputável. Com relação ao semi-imputável, o juiz deveria aplicar a pena com a redução decorrente de sua condição (art. 26, parágrafo único do Código Penal), devendo, em casos excepcionais, substituí-la por medida de segurança, nos termos do art. 98 do Código Penal ${ }^{182}$.

Pelo sistema vicariante, adotado pela Reforma da Parte Geral do Código Penal, a pena passou a ser a consequência jurídica decorrente da aplicação do sistema da culpabilidade e a medida de segurança, da aplicação do sistema da periculosidade.

\section{DISCIPLINA LEGAL VIGENTE}

A medida de segurança ${ }^{183}$ é a resposta jurídica cabível à pessoa com transtorno mental que praticou um fato tipificado como crime e que, por não possuir responsabilidade penal (inimputável), receberá uma sentença absolutória imprópria onde o juiz, ao invés de estabelecer uma pena, aplicará uma das espécies de medida de segurança.

O Código Penal, em seu art. 96, prevê duas espécies de medidas de segurança: a internação (art. 96, inciso I) e o tratamento ambulatorial (art. 96, inciso II).

A internação consiste no cumprimento da medida de segurança em hospital de custódia e tratamento psiquiátrico (HTCP) ou, à falta, em outro estabelecimento adequado. Nesta espécie de medida, o indivíduo é compulsoriamente internado pelo período determinado na sentença, para se submeter a tratamento psiquiátrico, objetivando o controle ou a cessação de sua periculosidade, de modo a permitir sua reinserção social.

A segunda espécie de medida de segurança é o tratamento ambulatorial. Nessa modalidade, é imposta ao indivíduo a necessidade de comparecimento regular e de submissão a tratamento médico-psiquiátrico, sem a obrigatoriedade de permanecer internado na instituição.

A regra, de acordo com o artigo 97 do Código Penal, é a imposição de internação ao inimputável que cometeu fato tipificado como crime punível com reclusão. Contudo, ressalta a lei penal que, se o crime for punido com detenção, poderá o juiz, se entender mais adequado, estabelecer a medida de tratamento ambulatorial ao invés da internação.

${ }^{182}$ CARVALHO, Salo de. Op. cit. p. 506.

${ }^{183}$ NUCCI afirma que Medida de Segurança “trata"-se de uma espécie de sanção penal, com caráter preventivo e curativo, visando a evitar que o autor de um fato havido como infração penal, inimputável ou semi-imputável, mostrando periculosidade, torne a cometer outro injusto e receba tratamento adequado. (NUCCI, Guilherme de Souza. Código Penal Comentado. Revista dos Tribunais. 13ª edição. 2013. p. 565). 
Definida a modalidade da medida de segurança, o juiz deverá fixar o seu tempo mínimo, entre 1 a 3 anos, conforme determina o artigo 97 do Código Penal. A medida de segurança imposta, seja a de internação ou a de tratamento ambulatorial, será por tempo indeterminado e perdurará enquanto não cessada a periculosidade do indivíduo, atestada por laudo pericial.

Tanto a espécie de medida de segurança - internação ou tratamento ambulatorial, quanto o tempo mínimo de cumprimento da medida, são estabelecidos por critério definido na lei penal, e não pela condição e necessidade da pessoa com transtorno mental em conflito com a lei.

A perícia médica deverá ser realizada anualmente ou em prazo menor, se assim determinar o juiz, para se verificar a cessação da periculosidade. Constatada a desnecessidade da manutenção da internação pela perícia, deverá o juiz determinar a transferência do indivíduo para o tratamento ambulatorial. Poderá ainda proceder a desinternação ou a liberação, que serão sempre condicionais, podendo o juiz reverter a decisão e determinar nova internação, se o indivíduo praticar fato indicativo de persistência de sua periculosidade.

A lei estabelece também, além da imposição da medida de segurança por sentença, a possibilidade de conversão da pena em medida de segurança, caso o apenado desenvolva transtorno mental que necessite de acompanhamento psiquiátrico. Uma vez convertida a pena em medida de segurança, a relação do indivíduo com o execução penal se dará apenas nesta modalidade de resposta jurídica e, mesmo reestabelecida a sanidade do indivíduo, não poderá ser revertida novamente em pena ${ }^{184}$.

\section{SISTEMA DE RESPONSABILIDADE ${ }^{185}$ PENAL BRASILEIRO}

\footnotetext{
${ }^{184}$ MIRABETE, Julio Fabbrini. Execução Penal. Editora Atlas. $8^{a}$ Edição. 1997. p. 411. Em sentido contrário, NUCCI entende ser possível a reconversão da medida de segurança em pena, para se evitar abuso. Afirma que "o caminho natural, para evitar qualquer tipo de subterfúgio, é converter a pena em medida de segurança, mas, melhorando o condenado, tornar a cumprir a sua pena, havendo portanto a reconversão. (...) Se a pena fosse convertida em medida de segurança, mas, pouco tempo depois, fosse constatada a melhora do condenado, caso pudesse conseguir a sua liberdade, muitas seriam as situações de injustiças”. (NUCCI, Guilherme de Souza. Op. cit. p. 571/572).

${ }^{185}$ NUCCI procura distinguir os conceitos de responsabilidade, imputabilidade e culpabilidade afirmando que “enquanto imputabilidade é a capacidade de ser culpável e culpabilidade é o juízo de reprovação social que pode ser realizado pelo imputável, responsabilidade é decorrência da culpabilidade, ou seja, trata-se da relação entre o autor e o Estado, que merece ser punido por ter cometido um delito. Os conceitos não se confundem, embora possam ser interligados". (NUCCI, Guilherme de Souza, op. cit. p. 293).
} 
A classificação do autor da conduta considerada ilícita como imputável ou inimputável e a consequente definição da resposta jurídica cabível (pena ou medida de segurança)

decorrem de uma opção política (político-criminal), posteriormente legitimada pela ciência jurídico-penal (dogmática penal), por fragmentar o sistema de responsabilidade criminal em dois distintos discursos de fundamentação: sistema de culpabilidade (imputabilidade/pena) e sistema de periculosidade (inimputabilidade/medida de segurança ${ }^{186}$.

Para a legislação penal brasileira, o inimputável é o indivíduo que, por doença mental ou desenvolvimento mental incompleto ou retardado, era, ao tempo da ação ou da omissão, inteiramente incapaz de entender o caráter ilícito do fato, ou de determinar-se de acordo com esse entendimento, tal como estabelece o artigo 26 do Código Penal. O imputável ${ }^{187}$, por sua

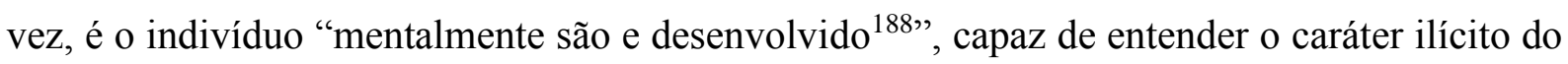
fato e dos seus efeitos, ou de determinar-se, de forma livre e consciente, de acordo com esse entendimento. A "maturidade em função da idade"189 (maior de 18 anos) é exigida tanto para o imputável, quanto para o inimputável. Enquanto imputabilidade ${ }^{190}$ é a regra, a inimputabilidade é a exceção.

A resposta jurídica cabível ao imputável é diversa da estabelecida ao inimputável. Ao imputável, a lei penal brasileira estabelece a aplicação de pena, como mecanismo retributivopunitivo pela conduta ilícita praticada. Ao inimputável, por ser inteiramente incapaz de entender o caráter ilícito ou de determinar-se por este entendimento, não seria adequada a aplicação de pena. Neste caso, a previsão legal é para a aplicação de medida de segurança, que tem finalidade terapêutica.

A pena aplicada ao autor da conduta ilícita, no sistema da culpabilidade, é a retribuição decorrente da prática de um fato passado e previamente definido como crime. No sistema de periculosidade, não há aplicação de pena, e sim de medida de segurança, que visa,

\footnotetext{
${ }^{186}$ CARVALHO, Saulo de. Op. cit. p. 501.

${ }^{187}$ O Código Penal no artigo 26 adotou o critério biopsicológico para a aferição da inimputabilidade do agente. Segundo Rogério Greco, "o critério biológico, portanto, reside na aferição da doença mental ou no desenvolvimento mental incompleto ou retardado. Contudo, mesmo que comprovado, ainda não será suficiente a fim de conduzir à situação de inimputabilidade. Será preciso verificar se o agente era, ao tempo da ação ou da omissão, inteiramente incapaz de entender o caráter ilícito do fato ou de determinar-se de acordo com esse entendimento (critério psicológio)" (GRECO, Rogério. Curso de Direito Penal - Parte Geral. Volume I. Editora Impetus. 15 Edição. 2013. p. 389). Também nesse sentido, NUCCI, Guilherme de Souza. Op. cit. p. 294.

188 JESUS, Damásio Evangelista de. Direito Penal - Parte Geral. $1^{\circ}$ volume. 20a edição. Editora Saraiva. 1997. p. 465.

189 BRANDÃO, Cláudio. A culpabilidade na dogmática penal. In: MENDES, Gilmar e Outros: Direito Penal Contemporâneo - Questões Controvertidas. Editora Saraiva. São Paulo, 2011. p. 208.

190 Segundo Rogério Greco, "para que o agente possa ser responsabilizado pelo fato típico e ilícito por ele cometido é preciso que seja imputável. A imputabilidade é a possibilidade de se atribuir, imputar o fato típico e ilícito ao agente". (GRECO, Rogério. Op. cit. p. 387).
} 
através de tratamento médico-psiquiatrico, conter a periculosidade do agente, de modo a evitar ocorrências de futuros delitos ${ }^{191}$.

A verificação da condição de inimputável se dá através da realização de exame de insanidade mental. Constatada a inimputabilidade da pessoa com transtorno mental, o juiz irá proferir uma sentença absolutória imprópria, aplicando uma medida de segurança, por tempo indeterminado, estabelecendo sua modalidade (internação ou tratamento ambulatorial) e o tempo mínimo de duração (de 1 a 3 anos), devendo a medida perdurar até que cessada a periculosidade do indivíduo.

No caso de constatação de semi-imputabilidade, o juiz irá proferir uma sentença condenatória, impondo uma pena reduzida, na forma do disposto no art. 26, parágrafo único do Código Penal, podendo substituir, contudo, por medida de segurança, se for mais adequada para o caso concreto.

\section{REFORMA PSIQUIÁTRICA DE 2001}

A Lei 10.216/2001, também conhecida como Lei Antimanicomial ou Lei da Reforma Psiquiátrica, veio contemplar

o modelo humanizador historicamente defendido pelos militantes do Movimento
Antimanicomial tendo como diretriz a reformulação do modelo de atenção à saúde
mental, transferindo o foco do tratamento que se concentrava na instituição
hospitalar para uma rede de atenção psicossocial, estruturada em unidades de
serviços comunitários e abertos ${ }^{192}$.

A Lei da Reforma Psiquiátrica contempla a possibilidade de acompanhamento do portador de transtorno mental, por equipe multidisciplinar, nas duas espécies de medida de segurança - internação e tratamento ambulatorial. Ela avança no sentido de vedar a internação de pacientes em instituições com características asilares, tais como manicômios e hospitais de custódia e tratamento psiquiátrico (HCTPs), priorizando o tratamento ambulatorial e somente admitindo a internação, em qualquer de suas modalidades, quando recursos extra-hospitalares se mostrarem insuficientes.

Independentemente de estar ou não em conflito com a lei, as pessoas com transtorno mental deverão receber tratamento e acompanhamento terapêutico nas mesmas unidades de

191 JESUS, Damásio Evangelista de. Op. cit. p. 536.

192 SILVA, Haroldo Caetano da. PAILI: Programa de Atenção Integral ao Louco Infrator. $3^{a}$ Edição. Goiânia: MP/GO. 2013. 
saúde ${ }^{193}$, sob pena de ofensa ao princípio da não-discriminação. O tratamento em regime de internação será estruturado de forma a oferecer assistência integral à pessoa com transtornos mentais, incluindo serviços médicos, de assistência social, psicológicos, ocupacionais, de lazer e outros.

O tratamento oferecido à pessoa com transtorno mental terá como finalidade permanente, a reinserção social do paciente em seu meio, visando seu resgate como cidadão, sujeito de direitos e deveres. A mudança de perspectiva com a reforma psiquiátrica objetiva uma maior integração e participação do paciente na condução de seu tratamento, afastando-se da ideia de assujeitamento ${ }^{194}$ comumente vista nos estabelecimentos de características asilares. $\mathrm{O}$ foco passa da doença para a pessoa.

A pessoa com transtorno mental passa a contar, com a Lei da Reforma Psiquiátrica, com um regime jurídico de proteção de direitos fundamentais, que lhe garante um tratamento com humanidade e respeito e no interesse exclusivo de beneficiar sua saúde. Além disso, busca alcançar a recuperação pela sua inserção na família, no trabalho e na comunidade.

A Reforma Psiquiátrica provocou a mudança de paradigma quanto ao tratamento dispensado à pessoa portadora de transtorno mental, bem como permitiu, como será exposto a seguir, uma nova interpretação dos dispositivos penais que regulam a aplicação da medida de segurança, que afasta seu caráter retributivo-punitivo-segregatório.

\section{CRÍTICAS AO INSTITUTO DA MEDIDA DE SEGURANÇA}

A reforma psiquiátrica reacendeu o debate quanto à aplicação da medida de segurança como resposta jurídica à pessoa com transtorno mental em conflito com a lei. A possibilidade de perpetuidade da medida de segurança, o tratamento discriminatório comparado com o apenado, a inexistência de um regime jurídico de direitos e garantias fundamentais e o caráter retributivo-punitivo são as críticas mais presentes.

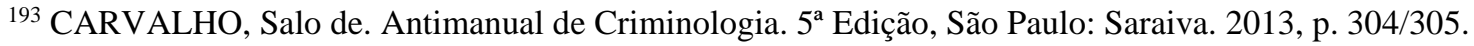

${ }^{194}$ Fernanda Barros descreve o cenário do indivíduo segregado em instituições asilares ao afirmar que "não se trata ao se segregar, sabemos que o abandono, o isolamento, a privação do movimento não caminham no sentido das saídas civilizadoras, ao contrário, é uma entrega à morte, o encontro com um resto radical sem condição de engajamento. (...). Sabemos dos efeitos catastróficos da privação do movimento, privação da liberdade de fazer laços: a entrada em qualquer hospício, manicômio, prisão, manicômio judiciário nos faz imediatamente perceber os efeitos da privação da liberdade, pois ali encontramos nos corpos a descrição das consequências clínicas do encarceramento". (BARROS, Fernanda Otoni de. Alternativas ao modelo prisional e manicomial: Metodologia/política/ampliação Subjetividade e inclusão - A experiência do PAI-PJ. IN: OLIVEIRA, Rodrigo Tôrres; MATTOS, Virgílio (Org.). Estudos de Execução Criminal Direito e Psicologia Belo Horizonte Tribunal de Justiça de Minas Gerais 2009).
} 
A legislação penal brasileira permite que a medida de segurança possa ser aplicada por tempo indeterminado, enquanto não verificada por perícia médica, a cessação de periculosidade. Esta mesma indeterminação temporal não é aplicada ao imputável, que possui proteção constitucional da vedação da aplicação da pena perpétua ${ }^{195}$. Ao apenado é garantida a individualização da pena e sua fixação dentro dos limites estabelecidos pela lei penal ${ }^{196}$.

Ao invocar a periculosidade como fundamento para a manutenção da medida de segurança por tempo indeterminado, o sistema penal brasileiro legitima o controle penal que, eventualmente, pode ser até mais severo do que o da pena, dando à medida de segurança, um caráter retributivo-punitivo. A ausência de limitação constitucional do tempo de duração da medida contribui para a manutenção do caráter de perpetuidade em desfavor do inimputável.

O debate em torno da possibilidade da perpetuidade da medida de segurança permitiu que alternativas fossem construídas para contornar o problema. São elas: 1) a duração da medida de segurança pelo prazo máximo de 30 anos, equivalente ao máximo de cumprimento de pena do imputável; 2) duração da medida de segurança pelo prazo equivalente ao máximo da pena culminada em abstrato; e 3) duração da medida de segurança pelo prazo equivalente ao da pena em concreto, caso o indivíduo fosse imputável.

A primeira possibilidade procura afastar o caráter de perpetuidade, aplicando para a medida de segurança o mesmo limite estabelecido aos apenados, qual seja, de 30 (trinta) anos, para a duração máxima da pena ${ }^{197}$. O Supremo Tribunal Federal tem julgamento neste sentido, estabelecendo que a medida de segurança deve perdurar enquanto não haja cessado a periculosidade do agente, limitada, contudo ao período máximo de trinta anos (Supremo Tribunal Federal, Habeas Corpus 97.621, Rel. Min. Cezar Peluso, j. 02.06.2009 e Habeas Corpus 84.219, Rel. Min. Marco Aurélio).

A segunda possibilidade considera a limitação do tempo da medida de segurança pelo cálculo do máximo da pena em abstrato, correspondente ao fato tipificado como crime cometido pela pessoa com transtorno mental. Seria uma hipótese mais branda do que o limite de 30 (trinta) anos e que também afastaria o caráter de perpetuidade da medida. Contudo, não leva em conta o princípio da individualização da medida de segurança, permitindo a aplicação

\footnotetext{
195 Artigo 50, inciso XLVII, alínea “b” da Constituição Federal: Não haverá penas: (...); b) de caráter perpétuo.

${ }^{196}$ Artigo 5 $5^{\circ}$, inciso XLVI - a lei regulará a individualização da pena (...).

${ }^{197}$ Código Penal, art. 75 - O tempo de cumprimento das penas privativas de liberdade não pode ser superior a 30 (trinta) anos.
} 
de um controle penal mais severo do que seria para o imputável ${ }^{198}$. Neste sentido, Superior Tribunal de Justiça, Habeas Corpus 122.522, Rel. Min. Og Fernandes, j. 18.08.2010.

A terceira possibilidade considera o limite máximo da medida de segurança, pelo cálculo da pena em concreto, tal como ocorreria com o imputável. O juiz estabeleceria o tempo da medida, considerando as circunstâncias judiciais, os agravantes e atenuantes, bem como as causas de aumento e diminuição. Após apurado o tempo de pena em concreto, o juiz o utilizaria como parâmetro para estabelecer o limite de cumprimento da medida de segurança, de forma a promover um tratamento isonômico entre imputável e inimputável. Além disso, permitiria a proporcionalidade na resposta jurídica cabível ao inimputado. "O procedimento é absolutamente adequado, inclusive para fins de orientação dos prazos prescricionais e definição dos direitos inerentes à execução das medidas de segurança ${ }^{199 "}$.

Rogério Greco, ao tratar a medida de segurança como remédio e não como pena, entende que a pessoa com transtorno mental sujeito a medida de segurança não pode ser completamente liberado se ainda demonstrar que "se não corretamente submetido a um tratamento médico, voltará a trazer perigo para si próprio, bem como para aqueles que com ele convivem" 200 . Contudo entende que no caso do semi-imputável que teve a pena convertida para a medida de segurança, seu tempo de duração jamais poderá ser superior ao tempo da condenação do agente, sob pena de agravar sua situação ${ }^{201}$.

Nucci entende não ser inconstitucional ${ }^{202}$ a medida de segurança ter duração indeterminada. Defende que a situação do agente deve ser analisada no momento da prática delitiva, para evitar o duplo binário, abolido da legislação penal brasileira com a Reforma da Parte Geral em 1984. Afirma que

\begin{abstract}
Se era inimputável, pode receber medida de segurança por tempo indeterminado, já que essa é a sanção merecida pelo que praticou. Sendo imputável, cabe-lhe a aplicação de uma pena, que não deve ser alterada no meio da execução por uma medida indeterminada. Afinal, de uma pena com limite pré-fixado, com trânsito em julgado, passaria o condenado a uma sanção sem limite 203 .
\end{abstract}

\footnotetext{
198 CARVALHO, Salo de. Penas e medidas de segurança no direito penal brasileiro: fundamentos e aplicação judicial. São Paulo: Saraiva. 2013. p. 513.

${ }^{199}$ CARVALHO, Amilton Bueno. Garantismo Penal Aplicado à Execução Penal. Rio de Janeiro: Lumen Juris, 2007. p. 202, apud CARVALHO, Salo de. Op. cit. p. 515.

${ }^{200}$ GRECO, Rogério. Op. cit. p. 677.

${ }^{201}$ GRECO, Rogério. Op. cit. p. 679.

202 Para Virgílio de Mattos, a Medida de Segurança não foi “recepcionada pela Constituição da República que veda sanção de caráter perpétuo. Não é preciso nenhum contorcionismo exegético para entender que a sanção da medida de segurança tem o caráter de pena e inscreve-se na vedação constitucional". O autor se refere à vedação do artigo 50, inciso XLVII, "b," da Constituição Federal. (MATTOS, Virgílio de. Canhestros caminhos retos: Notas sobre a segregação prisional do portador de sofrimento mental infrator. Revista brasileira de crescimento e desenvolvimento humano. Vol. 20, n.1 São Paulo abr. 2010).

${ }^{203}$ NUCCI, Guilherme de Souza. Op. cit. p. 570/571.
} 
Nucci entende ainda que, apesar da medida de segurança possuir um caráter de sanção penal, ela não deixa de ter um propósito curativo e terapêutico e que o indivíduo deveria permanecer em tratamento, sob a custódia do Estado, até que devidamente curado. Destaca que

\begin{abstract}
Muitos condenados a vários anos de cadeia estão sendo interditados civilmente, para que não deixem a prisão, por serem perigosos, padecendo de enfermidades mentais, justamente porque atingiram o teto fixado pela lei (30 anos). Ademais, apesar de seu caráter de sanção penal, a medida de segurança não deixa de ter o propósito curativo e terapêutico. Ora, enquanto não for devidamente curado, deve o sujeito submetido à internação permanecer em tratamento, sob custódia do Estado. Seria demasiado apego à forma transferi-lo de um hospital de custódia e tratamento criminal para outro, onde estão abrigados insanos interditados civilmente, somente porque foi atingido o teto máximo da pena correspondente ao fato criminoso praticado, como alguns sugerem, ou o teto máximo de 30 anos, previsto no art. 75 como sugerem outros $^{204}$.
\end{abstract}

Além da possibilidade de aplicação da medida de segurança por tempo indeterminado, a lei penal estabelece a fixação, pelo juiz, de um prazo mínimo de duração da internação ou do tratamento ambulatorial. Levando-se em consideração a possibilidade da pessoa com transtorno mental obter êxito no tratamento, com a consequente cessação da periculosidade, antes do fim do prazo mínimo determinado, tem-se que o estabelecimento deste tempo mínimo, estenderá o controle penal por tempo desnecessário, o que novamente evidenciaria seu caráter retributivo-sancionatório.

Se ao contrário, não houvesse o estabelecimento do prazo mínimo de duração da medida de segurança pela lei, restaria afastada a possibilidade de extensão da medida, de forma desnecessária, por este motivo. Poderia o juiz, a qualquer tempo, na forma da lei de execução penal ${ }^{205}$, determinar nova avaliação médica para aferição da cessação da periculosidade, que, uma vez constatada, evitaria o constrangimento desnecessário do indivíduo.

A vinculação da espécie de medida de segurança ao regime prisional (reclusão ou detenção) previsto para o fato tipificado como crime praticado pelo inimputável, também revela a intenção retributiva-punitiva do instituto. $\mathrm{O}$ critério definido pela lei penal não tem qualquer relação com a necessidade do indivíduo, possibilitando a aplicação de uma espécie de medida de segurança inadequada e mais severa.

\footnotetext{
${ }^{204}$ NUCCI, Guilherme de Souza. Op. cit. p. 568.

205 Art. 176. Em qualquer tempo, ainda no decorrer do prazo mínimo de duração da medida de segurança, poderá o Juiz da execução, diante de requerimento fundamentado do Ministério Público ou do interessado, seu procurador ou defensor, ordenar o exame para que se verifique a cessação da periculosidade (...).
} 
O fundamento para a imposição de internação ou de tratamento ambulatorial é justamente o fato de o indivíduo ter transtorno mental e necessitar de tratamento médicopsiquiátrico adequado para ver cessada sua periculosidade. Não faz nenhum sentido, a nosso ver, determinar uma internação, pelo fato do crime ser punível com reclusão, para alguém que basta o tratamento ambulatorial, a não ser que se pense em seu caráter retributivo ${ }^{206}$.

Além disso, a vinculação da espécie de medida ao regime prisional choca com as diretrizes da Lei de Reforma Psiquiátrica que preconiza que a internação somente deverá ocorrer, quando os recursos extra-hospitalares se mostrarem ineficientes. A lei antimanicomial tornou subsidiária a internação, devendo o juiz preferir o tratamento ambulatorial, sempre que este for o mais adequado.

Admitindo o estabelecimento de tratamento ambulatorial ao invés de internação, na forma acima exposta, o Supremo Tribunal Federal decidiu que "em casos excepcionais, admite-se a substituição da internação por medida de tratamento ambulatorial quando a pena estabelecida para o tipo é a reclusão, notadamente quando manifesta a desnecessidade da internação" (Supremo Tribunal Federal, Habeas Corpus 85.401, Rel. Min. Cezar Peluzo, j. 04.12.2009).

A pessoa com transtorno mental sujeita à medida de segurança não conta em seu favor, com um regime jurídico de direitos e garantias fundamentais estabelecidos nas leis penal, processual e de execução penal, tal como acontece com o imputável. Direitos penais materiais, tais como as causas de exclusão da tipicidade (princípio da insignificância e princípio da adequação social), da ilicitude (consentimento do ofendido), da própria culpabilidade (coação moral irresistível, erro de proibição inevitável, inexigibilidade de conduta diversa) e da punibilidade (prescrição) encontram previsão legal apenas em favor do imputável. Direitos e garantias processuais também não alcançam os inimputáveis, tais como a composição civil, a transação penal e a suspensão condicional do processo. No âmbito da execução das medidas de segurança, são excluídos inúmeros direitos assegurados aos presos como a remição, a detração, a progressão de regime e o livramento condicional ${ }^{207}$.

A diferença do sistema de responsabilização penal do inimputável em comparação com o imputável talvez seja a justificativa para o tratamento diferenciado. Contudo, tal como já analisado, a medida de segurança possui uma face retributivo-punitiva que justificaria a

\footnotetext{
${ }^{206}$ No sentido da faculdade do julgador definir a espécie de medida de segurança mais adequada de acordo com a necessidade da pessoa com transtorno mental, GRECO, Rogério. Op. cit. p. 674; CARVALHO, Salo de. Op. cit. p. 512. NUCCI, Guilherme de Souza. Op. cit. p. 568.

${ }^{207}$ Nesse sentido, CARVALHO, Salo de. Op. cit. p. 515; e CRUZ, Marcelo Lebre. A inconstitucionalidade da medida de segurança face a periculosidade criminal. Dissertação. 2009. p. 201.
} 
extensão do regime jurídico de direitos e garantias fundamentais do apenado ao inimputável ${ }^{208}$.

Além disso, a restrição decorrente da adoção de sistema de responsabilidade distinta nega, ao indivíduo em condição especial (pessoa com transtorno mental e que necessita de uma maior proteção) os direitos e garantias já assegurado aos imputáveis. Essa restrição promove um tratamento discriminatório e não isonômico sujeitando o indivíduo submetido à medida de segurança, a um controle penal mais severo.

É possível ainda, à luz da reforma psiquiátrica, interpretar a lei penal, processual e de execução penal estendendo o regime jurídico de direitos e garantias dos apenados aos inimputáveis, na medida em que se entende que a reforma procurou atribuir responsabilidade à pessoa com transtorno mental, o que permitiria sua inclusão no sistema de culpabilidade, afastando a aplicação da periculosidade como fundamento da coação estatal.

\section{CRÍticas AOS CONCEITOS DE PERICUlOSIDADE E DE INIMPUTABILIDADE}

A reforma psiquiátrica de 2001 promoveu uma mudança de paradigma na forma de se relacionar com a pessoa com transtorno mental. Busca o tratamento humanizado e o respeito ao indivíduo, visando alcançar sua recuperação pela inserção na família, no trabalho e na comunidade. Também objetiva uma maior participação deste indivíduo, fornecendo-lhe informações a respeito da doença e dos rumos do tratamento, aumentando seu compromisso e responsabilidade. Além disso, tem como finalidade permanente, sua reinserção social no seu meio.

Esta nova concepção é diferente do que se preconiza no artigo 26 do Código Penal, onde a pessoa com transtorno mental é vista como alguém sem qualquer responsabilidade, incapaz de responder por seus atos, sendo compelida à internação compulsória ou ao tratamento ambulatorial, com o objetivo de cessação de sua periculosidade.

Essa mudança de perspectiva, trazida pela Lei de Reforma Psiquiátrica, que não faz distinção entre a pessoa com transtorno mental que está ou não em conflito com a lei, fez ressurgir a discussão a respeito dos conceitos de inimputabilidade e de periculosidade. A maior preocupação com o indivíduo, revelada pela Lei de Reforma Psiquiátrica, fez com que o debate sobre a responsabilidade do portador de transtorno mental voltasse à cena.

${ }^{208}$ CARVALHO, Salo de. Op. cit. p. 515. 
É possível dizer que a lei antimanicomial ao afirmar que sua finalidade permanente é a reinserção social da pessoa com transtorno mental em seu meio, afasta a aplicação da periculosidade como sistema de responsabilidade penal, subsistindo, a partir dela, apenas o sistema da culpabilidade. O foco deixa de ser a doença e passa a ser a pessoa, a preocupação com o ser humano e a necessidade de restaurar sua cidadania e dignidade. A reinserção social, e não mais a cessação de periculosidade, passa a ser o objetivo do tratamento terapêutico.

De certa forma, a lei antimanicomial procura afastar a incidência do sistema da periculosidade, promovendo o debate em torno de um único sistema, qual seja, o da culpabilidade, na medida em que estabelece como foco a pessoa, seu tratamento e sua reinserção social, ao invés da contenção da periculosidade. Assim, se consubstancia em importante mecanismo de resistência a uma tendência punitivista, que procura a cada dia enfraquecer o critério da culpabilidade e prestigiar o critério da periculosidade ${ }^{209}$, na direção da "expansão do direito penal" 210 , denunciada por Silva Sánchez (pela criminalização de condutas e pelo recrudescimento das penas).

O abandono da periculosidade, como fundamento da medida de segurança, permitiria um tratamento isonômico entre a pessoa com transtorno mental e o apenado, consistente na extensão do regime jurídico de direitos e garantias de direitos fundamentais a todos - direitos materiais penais, processuais e de execução penal.

Também é possível pensar na inadequação da expressão "medida de segurança", uma vez reconhecido o abandono da periculosidade como fundamento da medida de controle penal. Em seu lugar, poderia o juiz, estabelecer somente o tratamento adequado (internação ou tratamento ambulatorial), em face da necessidade da pessoa com transtorno mental ${ }^{211}$.

Tendo a Reforma Psiquiátrica deixado de utilizar o termo “doença mental”, passando a fazer uso da expressão portador de transtorno mental, é possível considerar a necessidade de readequação do conceito de inimputabilidade. A atribuição de certo grau de responsabilização à pessoa com transtorno mental em conflito com a lei, bem como a abdicação da utilização do termo "doente mental", poderiam levar ao entendimento do abandono do conceito de

\footnotetext{
${ }^{209}$ GOMES, Mariângela Gama de Magalhães. Periculosidade no Direito Penal contemporâneo. IN: MENDES, Gilmar; BOTTINI, Pierpaolo Cruz; PACELLI, Eugênio (Org.). Direito Penal Contemporâneo. Questões Controvertidas. São Paulo: Saraiva, 2011. p. 251.

${ }^{210}$ SÁNCHEZ, Jesús-María Silva. A Expansão do Direito Penal. Aspectos da política criminal nas sociedades

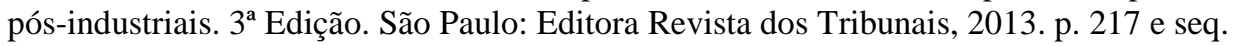

${ }^{211}$ JACOBINA, Paulo Vasconcelos. Direito Penal da loucura e reforma psiquiátrica. Brasília. ESMPU, 2008 , p. 137.
} 
inimputabilidade ou mesmo da necessidade de sua readequação, visto que sua definição se funda justamente na ausência de responsabilidade do agente com doença mental ${ }^{212}$.

Dentro da perspectiva da readequação do conceito de inimputabilidade, e procurando afastar-se de um modelo punitivista, é possível se pensar em um sistema de responsabilização onde o indivíduo tem a sua conduta valorada assim como acontece com o apenado, mas, ao final do processo de individualização e dosimetria, teria substituída a pena pela medida de segurança.

Duas possibilidades surgem a partir desta hipótese: a da individualização da pena tal como seria aplicada ao imputável, com a posterior substituição por medida de segurança ${ }^{213}$; e a valoração, com a redução da pena na forma do artigo 26, caput do Código Penal, que regula a semi-imputabilidade. Nesta segunda possibilidade, também haveria a substituição da pena aplicada por medida de segurança ${ }^{214}$.

Dentro da perspectiva de abandono do conceito de inimputabilidade e de atribuição de responsabilização penal da pessoa com transtorno mental, o juiz iria aplicar a pena, com a devida individualização, assegurando ao imputado, a aplicação de uma atenuante genérica, quando houver relação entre a patologia e o crime. O individuo cumpriria a pena juntamente com os demais apenados e, em momentos de crise, poderia cumpri-la em hospital penitenciário $^{215}$.

Por outro prisma, Zaffaroni e Batista defendem que, diante da Lei da Reforma Psiquiátrica, o direito penal não mais deveria se ocupar de situações envolvendo "pessoas incapazes de culpabilidade que tenham protagonizado um conflito criminalizado"216, afirmando que essas questões deveriam ficar a cargo do juiz cível, buscando dar efetividade às disposições do direito psiquiátrico (Lei 10.216/01).

A lei da reforma psiquiátrica ao atribuir responsabilidade ao portador de transtorno mental na condução de seu tratamento, não procurou e não estendeu esta responsabilidade para o âmbito penal, cível ou mesmo administrativo. Carvalho, no entanto, nos convida à

\footnotetext{
${ }^{212}$ CARVALHO, Salo de. Op. cit. p. 525.

${ }^{213}$ QUEIROZ, Paulo. Direito Penal, p. 458, apud CARVALHO, Salo de. Op. cit. p. 527

${ }^{214}$ CARVALHO, Salo de. Op. cit. p. 529. O autor propõe à pessoa com transtorno mental em conflito com a lei um tratamento jurídico similar ao da semi-imputabilidade. "Isto porque, se a lei 10.216/2011 reconhece o usuário do sistema de saúde mental como um sujeito com capacidades diferenciadas de compreensão (cognição) e vontade, em termos penais este quadro se assemelha muito às formas de culpabilidade reduzida".

${ }^{215}$ Mattos, Virgílio. Crime e Psiquiatria, p. 168, apud CARVALHO, Salo de. Op. cit. p. 527.

216 ZAFFARONI, E. Raúl; BATISTA, Nilo; ALAGIA, Alejandro; SLOKAR, Alejandro. Direito Penal Brasileiro. Vol 1 - Teoria Geral do Direito Penal. Rio de Janeiro: Revan, 2003, $4^{\text {a }}$ edição, p. 139.
} 
reflexão sobre a possibilidade de pensar em atribuição de responsabilidade nas esferas cível e administrativa, diante do novo paradigma introduzido pela lei antimanicomial ${ }^{217}$.

Não se pode negar, contudo, o avanço proporcionado pela Reforma Psiquiátrica de 2001, para considerar a pessoa com transtorno mental como sujeito de direitos, visando não mais o controle da periculosidade, mas sua reinserção social, buscando o resgate de sua cidadania, afastando-o do processo de coisificação decorrente do modelo asilar das instituições totais.

\section{CONSIDERAÇÕES FINAIS}

A reforma psiquiátrica introduziu um novo paradigma na aplicação da medida de segurança, visto estabelecer que a pessoa com transtorno mental em conflito com a lei deverá receber um tratamento humanizado, não discriminatório, que permita sua reinserção no meio social, procurando tratá-la como sujeito de direitos e deveres, restaurando sua cidadania.

O novo paradigma não mais admite a internação em manicômios judiciais. Também não admite que a espécie de medida de segurança cabível seja vinculada ao tipo de crime praticado, e sim, ao adequado tratamento de acordo com a necessidade terapêutica do indivíduo.

Abandona-se a perspectiva da periculosidade para focar no tratamento e na reinserção social. Assim, o sistema da periculosidade deixa de ser compatível com a norma decorrente da interpretação da Lei Antimanicomial.

Os direitos e garantias assegurados aos apenados podem e devem ser estendidos às pessoas portadores de transtorno mental em conflito com a lei, permitindo-lhes um tratamento isonômico que não faça da medida de segurança uma resposta jurídica mais gravosa do que a pena imposta, pela prática do mesmo fato tipificado como crime.

A atribuição de certo grau de responsabilização à pessoa com transtorno mental em conflito com a lei, bem como a abdicação da utilização do termo "doente mental", poderiam levar ao entendimento do abandono do conceito de inimputabilidade ou mesmo da

\footnotetext{
217 CARVALHO, Salo de. Op. cit. p 532. Ao autor entende que a lei de reforma psiquiátrica não impediria pensar na exclusiva responsabilização do portador de sofrimento psíquico no âmbito cível ou na esfera administrativa. "Neste espaço alheio ao jurídico-penal, a finalidade da intervenção judicial seria direcionada ao estabelecimento dos critérios de compensação da vítima pelos danos materiais e morais causados pela conduta ilícita, sem qualquer necessidade de ingerência das agências de punitividade".
} 
necessidade de sua readequação, visto que sua definição se funda justamente na ausência de responsabilidade do agente com doença mental.

Mesmo sob o novo paradigma, que busca atribuir responsabilidade à pessoa com transtorno mental, com relação aos rumos de seu tratamento terapêutico, não é possível entender que também lhe tenha sido atribuída responsabilidades cível ou administrativa, decorrentes do fato típico praticado. Ainda não se pode falar em sua responsabilização, salvo pelos rumos de seu tratamento.

Por fim, retomando o Caso Cadu, durante o curso da medida de segurança, já na espécie de tratamento ambulatorial, foi-lhe atribuída responsabilidade pelos rumos de seu tratamento; buscou-se sua reinserção social. A responsabilização penal que lhe foi imposta em 2015, não decorre de seu comportamento anterior, de 2010, mas de sua nova conduta, praticada no curso da medida de segurança, em condições em que era capaz de entender o caráter ilícito do fato e dos seus efeitos, ou de determinar-se, de forma livre e consciente, de acordo com esse entendimento. O novo laudo afastou a inimputabilidade ou mesmo a semiimputabilidade. Cadu foi morto durante o cumprimento da pena, em 2016.

\section{REFERÊNCIAS}

BARROS, Fernanda Otoni de. Alternativas ao modelo prisional e manicomial: Metodologia/política/ampliação Subjetividade e inclusão - A experiência do PAI-PJ. IN: OLIVEIRA, Rodrigo Tôrres; MATTOS, Virgílio (Org.). Estudos de Execução Criminal Direito e Psicologia Belo Horizonte Tribunal de Justiça de Minas Gerais 2009.

BRANDÃO, Cláudio. A culpabilidade na dogmática penal. In: MENDES, Gilmar e Outros: Direito Penal Contemporâneo - Questões Controvertidas. Editora Saraiva. São Paulo, 2011.

CARVALHO, Salo de. Penas e medidas de segurança no direito penal brasileiro: fundamentos e aplicação judicial. São Paulo: Saraiva. 2013.

CARVALHO, Salo de. Antimanual de Criminologia. 5a Edição, São Paulo: Saraiva. 2013.

CRUZ, Marcelo Lebre. A inconstitucionalidade da medida de segurança face a periculosidade criminal. $\quad$ Dissertação. $2009 . \quad 201$. http://www.unibrasil.com.br/sitemestrado/_pdf/marcelo_lebre.pdf 
GOMES, Mariângela Gama de Magalhães. Periculosidade no Direito Penal contemporâneo. IN: MENDES, Gilmar; BOTTINI, Pierpaolo Cruz; PACELLI, Eugênio (Org.). Direito Penal Contemporâneo. Questões Controvertidas. São Paulo: Saraiva, 2011.

GRECO, Rogério. Curso de Direito Penal - Parte Geral. Volume I. Editora Impetus. 15 Edição. 2013.

JACOBINA, Paulo Vasconcelos. Direito Penal da loucura e reforma psiquiátrica. Brasília. ESMPU, 2008.

JESUS, Damásio Evangelista de. Direito Penal - Parte Geral. $1^{\circ}$ volume. 20ª edição. Editora Saraiva. 1997.

MATTOS, Virgílio de. Canhestros caminhos retos: Notas sobre a segregação prisional do portador de sofrimento mental infrator. Revista brasileira de crescimento e desenvolvimento humano. Vol. 20, n.1 São 2010. http://pepsic.bvsalud.org/scielo.php?script=sci_arttext\&pid=S0104-12822010000100008

MIRABETE, Julio Fabbrini. Execução Penal. Editora Atlas. 8a Edição. 1997.

NUCCI, Guilherme de Souza. Código Penal Comentado. Revista dos Tribunais. $13^{\mathrm{a}}$ edição. 2013.

PRADO, Alessandra Rapassi Mascarenhas. Tratamento Extra-Hospitalar: Possibilidade de Adoção em Crimes Punidos com Reclusão. In: SCARPA, Antonio Oswaldo; EL HIRECHE, Gamil Foppel (Coord.). Temas de Direito Penal e Processual Penal - Estudos em homenagem ao Juiz Tourinho Neto. Salvador: Editora JusPodium, 2013.

SÁNCHEZ, Jesús-María Silva. A Expansão do Direito Penal. Aspectos da política criminal nas sociedades pós-industriais. 3ª Edição. São Paulo: Editora Revista dos Tribunais, 2013.

SILVA, Haroldo Caetano da. PAILI: Programa de Atenção Integral ao Louco Infrator. $3^{\text {a }}$ Edição. Goiânia: MP/GO. 2013.

ZAFFARONI, E. Raúl; BATISTA, Nilo; ALAGIA, Alejandro; SLOKAR, Alejandro. Direito Penal Brasileiro. Vol 1 - Teoria Geral do Direito Penal. Rio de Janeiro: Revan, 2003, 4 ${ }^{\text {a }}$ edição. 


\title{
THE (IN) SUSTAINABILITY OF THE CONCEPTS OF INIMPUTABILITY AND PERICULOSITY BEFORE THE PSYCHIATRIC REFORM.
}

\begin{abstract}
The objective of this article is to discuss the institute of the security measure as a modality of legal response, as well as concepts of dangerousness and non-attributability that relate to the institute, in light of the Psychiatric Reform (Law 10.216 / 01), which inaugurated a new Paradigm, having as focus no more the disease, but the person; Not the cessation of dangerousness, but the social reintegration of the person with mental disorder in conflict with the law.
\end{abstract}

Keywords: Security measure. Psychiatric reform: hazards. Incomputability. 